\title{
Disposable Carbon Dots Modified Screen Printed Carbon Electrode Electrochemical Sensor Strip for Selective Detection of Ferric Ions
}

\author{
Shao Chien Tan, Suk Fun Chin, and Suh Cem Pang \\ Department of Chemistry, Faculty of Resource Science and Technology, Universiti Malaysia Sarawak, \\ 94300 Kota Samarahan, Sarawak, Malaysia \\ Correspondence should be addressed to Suk Fun Chin; sukfunchin@gmail.com
}

Received 25 November 2016; Accepted 16 January 2017; Published 2 February 2017

Academic Editor: Biplab Paul

Copyright (C) 2017 Shao Chien Tan et al. This is an open access article distributed under the Creative Commons Attribution License, which permits unrestricted use, distribution, and reproduction in any medium, provided the original work is properly cited.

\begin{abstract}
A disposable electrochemical sensor strip based on carbon nanodots (C-Dots) modified screen printed carbon electrode (SPCE) was fabricated for selective detection of ferric ions $\left(\mathrm{Fe}^{3+}\right)$ in aqueous solution. C-Dots of mean diameters within the range of 1-7 $\mathrm{nm}$ were synthesized electrochemically from spent battery carbon rods. The analytical performance of this electrochemical sensor strip was characterized using cyclic voltammetry (CV) and electrochemical impedance spectroscopy (EIS). The deposition of C-Dots had enhanced the electron-transfer kinetics and current intensity of the SPCE remarkably by $734 \%$ as compared to that of unmodified SPCE. Under optimized conditions, the electrochemical sensor strip exhibited a linear detection range of 0.5 to $25.0 \mathrm{ppm} \mathrm{Fe} \mathrm{F}^{3+}$ with a limit of detection $(\mathrm{LOD})$ of $0.44 \pm 0.04 \mathrm{ppm}($ at $S / N$ ratio $=3$ ). Validation of results by the electrochemical sensor strip was done by comparing analysis results obtained using an Atomic Absorption Spectrometer (AAS).
\end{abstract}

\section{Introduction}

Ferric ions $\left(\mathrm{Fe}^{3+}\right)$ are transition metal ions which play essential roles in biological activities, such as oxygen carriers in haemoglobin [1] and growth nutrients for phytoplankton [2, 3]. Deficiency in iron can result in anemia [4], yet high level of iron in human body may result in serious health problems, for instance, Alzheimer and Parkinson diseases $[5,6]$. Iron may speed up the formation of reactive oxygen species in redox-active forms $[7,8]$; hence overdose of iron may result in diseases. Therefore it is important to monitor the level of iron in human body or in tap water supplies.

Conventionally, Atomic Absorption Spectroscopy (AAS) and Inductively Coupled Plasma Mass Spectroscopy (ICPMS) are being used for heavy metals analysis due to their wide range of detection and high sensitivity [9]. However, these instruments are costly, time-consuming, and bulky as well as not portable for on-site testing. Furthermore, samples have to be transported from sites to laboratories, and preservation of samples is normally required $[10,11]$. A portable, highly sensitive, and selective sensing system is highly desirable for rapid and accurate detection of heavy metals ions especially for in situ environmental monitoring.

Several ion-selective electrodes for detection of $\mathrm{Fe}^{3+}$ have been reported. An ion-selective electrode based on $\mu$-bis(tridentate) ligand was shown to be highly selective towards $\mathrm{Fe}^{3+}$ with a limit of detection (LOD) of $0.276 \mathrm{ppm}$ (evaluated as $5.0 \times 10^{-6} \mathrm{M}$ ) [12]. Some researchers had proposed the use of poly(vinyl chloride) (PVC) membrane electrode incorporating $4,4^{\prime}$-dimethoxybenzil bisthiosemicarbazone (DBTS) and porphyrins as receptors [13, 14]. Fong et al. [15] had reported a fluorescence chemosensor based on carbon nanoparticles (CNP) synthesized from sodium alginate using nanoprecipitation and thermal acid carbonization method. This sensor worked by determining the fluorescence quenching of CNP in the presence of $\mathrm{Fe}^{3+}$ and a LOD of $1.06 \mu \mathrm{M}$ was reported. However, these sensors for $\mathrm{Fe}^{3+}$ ions still posed challenges of requiring the use of hazardous or expensive chemicals and complicated fabrication process. Therefore, a low-cost, portable, ecofriendly, and highly sensitive electrochemical sensor is highly desirable for on-site rapid detection of $\mathrm{Fe}^{3+}$ ions. 
Herein, we report a disposable, sensitive, and selective detection of $\mathrm{Fe}^{3+}$ ions using C-Dots modified SPCE based electrochemical sensor strip. C-Dots were derived electrochemically from spent battery carbon rods, using a cost effective and ecofriendly process which involved the use of only ultrapure water as the electrolyte. Spent battery carbon rods served as the carbon source in the preparation of C-Dots, which were, in turn, used for the fabrication of electrochemical sensor. As-prepared C-Dots were observed to be selective towards $\mathrm{Fe}^{3+}$ ions without the need of surface modification as demonstrated by this work.

\section{Experimental}

2.1. Reagents and Materials. All chemicals were purchased from Sigma-Aldrich Company, Merck Company, and Hamburg Company. Ultrapure water $\left(\sim 18.2 \mathrm{M} \Omega \cdot \mathrm{cm}, 25^{\circ} \mathrm{C}\right)$ was prepared using the Water Purifying System (ELGA Model Ultra Genetic). Hydrochloric acid $(\mathrm{HCl})$ was obtained from R\&M Chemicals. Carbon rods of spent EVEREADY Super Heavy Duty AA size primary battery were used for the preparation of C-Dots. Screen printed carbon electrodes (SPCE) consisting of carbon-based working and counterelectrodes and a silver/silver chloride $(\mathrm{Ag} / \mathrm{AgCl})$ reference electrode were purchased from a local vendor, Rapid Labs Sdn Bhd. Mineral water was purchased from Blue Ice Natural Mineral Water.

2.2. Electrochemical Preparation of C-Dots. C-dots were prepared by adopting the previously reported method [16]. A direct current power supply (GPR-6030D) was used as the power source. Two carbon rods (diameter $=0.48 \mathrm{~mm}$ ) were used as both anode and cathode which were set parallel to each other and separated at a distance of $5 \mathrm{~cm}$ in $200 \mathrm{~mL}$ of ultrapure water. A constant voltage $(50 \mathrm{~V})$ was applied to the electrochemical cell and the electrolyte was constantly stirred for 96 hours. At the end of the process, the electrolyte turned black indicating the formation of C-Dots. The electrolyte was filtered using the quantitative filter disc Sartorius Grade 390. The filtrate dispersion was centrifuged at 13,500 RPM for $30 \mathrm{~min}$ to remove coarse graphite particles, and the supernatant was oven-dried at $80^{\circ} \mathrm{C}$ to obtain C-Dots.

2.3. Characterization of C-Dots. The size and morphology of C-Dots were characterized using a transmission electron microscope (TEM) (JEOL JEM 1230). UV-Vis absorption spectra of the C-Dots were measured using a UV/Vis spectrophotometer (Jasco V-630). Fourier Transform Infrared (FTIR) spectra of C-Dots were obtained from $\mathrm{KBr} /$ sample pellets within the range of $400-4000 \mathrm{~cm}^{-1}$ using FTIR spectrometer (Thermo Scientific, Nicole iS10).

2.4. Fabrication and Characterization of C-Dots Modified SPCE Sensor Strip. Commercial SPCE strips were modified with C-Dots using a simple drop-coating method. Simply, $10 \mu \mathrm{L}$ of C-Dots dispersion was added onto the surface of working electrode of SPCE. The SPCE was then dried in an oven at $90^{\circ} \mathrm{C}$ for $10 \mathrm{~min}$. The C-Dots modified SPCE sensor strips were characterized by Cyclic voltammetry (CV) and electrochemical impedance spectroscopy (EIS) using a Potentiostat (Princeton Applied Research, PARSTAT 2263) in $0.01 \mathrm{M}$ of $\mathrm{HCl}$ with a scan rate of $100 \mathrm{mV} \mathrm{s}^{-1}$ within a potential scan range of -0.5 to $0.5 \mathrm{~V}$. The response of C-Dots modified SPCE strip was optimized by varying both the quantity of $\mathrm{C}$-Dots deposited and the concentration of $\mathrm{HCl}$ electrolyte. $10 \mu \mathrm{L}$ C-Dots dispersion of different concentrations (0.1$10.0 \mu \mathrm{g}$ ) was drop-coated onto the working electrode of SPCE and oven-dried. These C-Dots modified SPCE strips were characterized by $\mathrm{CV}$ and EIS. $\mathrm{HCl}$ solutions of different concentrations $(0.01-1.00 \mathrm{M})$ were purged with nitrogen gas for $5 \mathrm{~min}$ before use. Scheme 1 depicts the process on the fabrication of C-Dots modified SPCE working electrode.

2.5. Metal Ions Selective Study. Stock solutions of various metal ions at concentration of $25.0 \mathrm{ppm}$ were prepared. Among metal ions used for the selectivity studies included $\mathrm{Ba}^{2+}, \mathrm{Ca}^{2+}, \mathrm{Cd}^{2+}, \mathrm{Co}^{2+}, \mathrm{Fe}^{3+}, \mathrm{Hg}^{2+}, \mathrm{Na}^{+}, \mathrm{K}^{+}, \mathrm{Sn}^{2+}$, and $\mathrm{Zn}^{2+}$ ions. These metal ions were more commonly found in water and associated with heavy metal pollution. $10 \mu \mathrm{L}$ of these metal ions stock solutions was separately added dropwise onto the surface of C-Dots modified working electrode of SPCE, dried, and characterized by CV and EIS. Atomic Absorption Spectrophotometer (AAS) (Thermo Fisher Scientific TCE 3500) was used for determining the $\mathrm{Fe}^{3+}$ ions concentration in real water samples.

\section{Results and Discussion}

3.1. Preparation and Characterization of C-Dots. C-Dots of uniform size were successfully prepared by electrochemical oxidation of carbon rods of spent batteries. The preparation of carbon nanoparticles by electrochemical oxidation of graphite electrodes had been previously reported $[16,17]$. TEM micrograph of the as-prepared C-Dots is shown in Figure 1(a). The C-Dots were observed to be spherical in shape with a size range of $1-7 \mathrm{~nm}$ and a mean diameter of $2.9 \mathrm{~nm}$ (inset Figure 1(a)). Figure 1(b) shows the UV-Vis absorption spectrum with the characteristic absorption peak of C-Dots at $225 \mathrm{~nm}$ which was attributed to the $\pi-\pi$ transition of aromatic carbon $[16,18]$.

Figure 2(a) shows FTIR spectrum of spent battery carbon rod. Carbon rod showed 3 distinctive peaks at $3450 \mathrm{~cm}^{-1}(\mathrm{O}-$ $\mathrm{H}), 1635 \mathrm{~cm}^{-1}(\mathrm{C}=\mathrm{C})$, and $1422 \mathrm{~cm}^{-1}(\mathrm{C}-\mathrm{O})$ which were in consonance with functional groups of commercial graphite rod as reported in another work [16]. Figure 2(b) shows FTIR spectrum of as-synthesized C-Dots. Absorption peaks at $1585 \mathrm{~cm}^{-1}$ and $1415 \mathrm{~cm}^{-1}$ were attributed to the $\mathrm{COO}^{-}$group [19]. Absorption peaks at $3215 \mathrm{~cm}^{-1}$ and $1697 \mathrm{~cm}^{-1}$ were assigned to $\mathrm{O}-\mathrm{H}$ and $\mathrm{C}=\mathrm{O}$ [20], whereas peaks at $1228 \mathrm{~cm}^{-1}$ and $1089 \mathrm{~cm}^{-1}$ were attributed to $\mathrm{C}-\mathrm{O}$ stretching vibration [16]. As shown in the FTIR spectra, $\mathrm{COO}^{-}$groups were formed during electrochemical oxidation on the as-prepared C-Dots which therefore required no surface modification for their use in the detection of $\mathrm{Fe}^{3+}$ ions. 

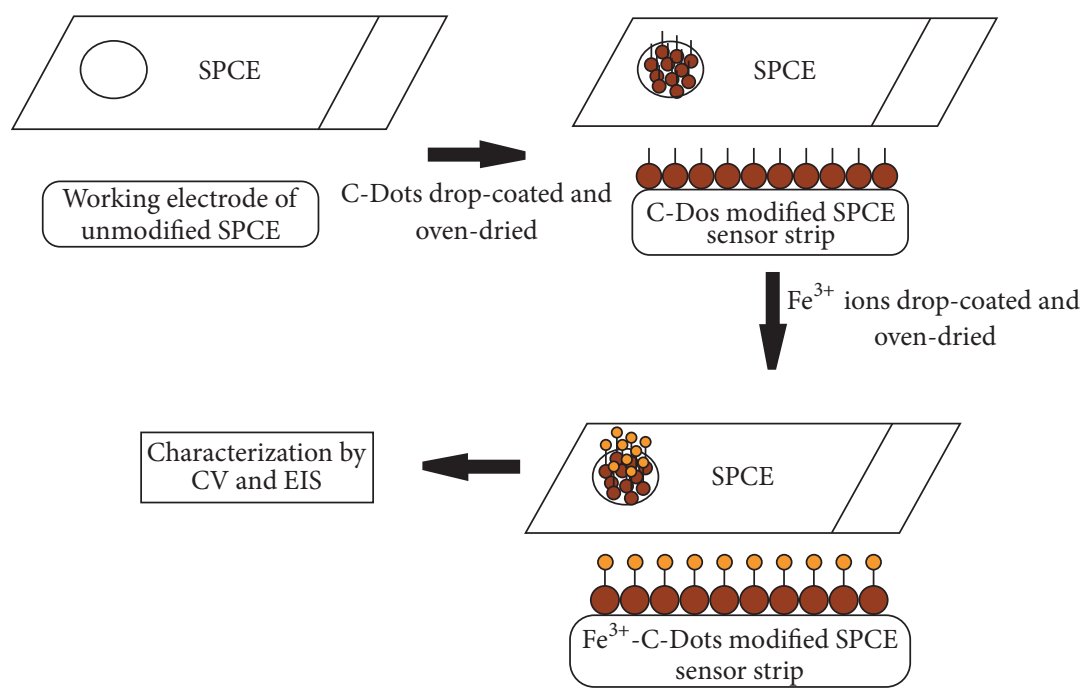

Scheme 1: Schematic diagram of the fabrication of C-Dots modified SPCE sensor strip and its use for the detection of Fe ${ }^{3+}$ ions.

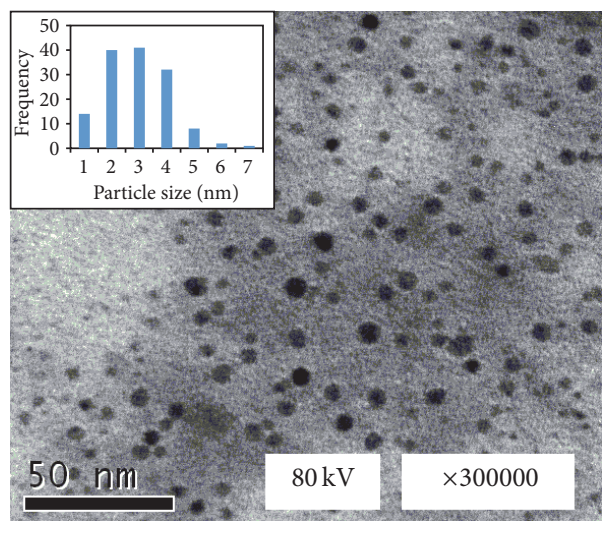

(a)

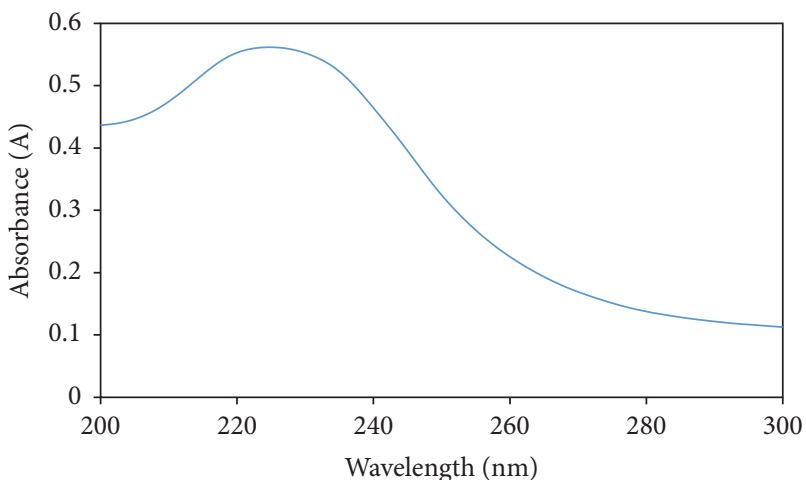

(b)

FIGURE 1: (a) TEM micrograph of C-Dots electrochemically synthesized from carbon rods of spent batteries. (b) UV-Vis absorption spectrum of C-Dots. Inset in (a) shows the particle size distribution of C-Dots.

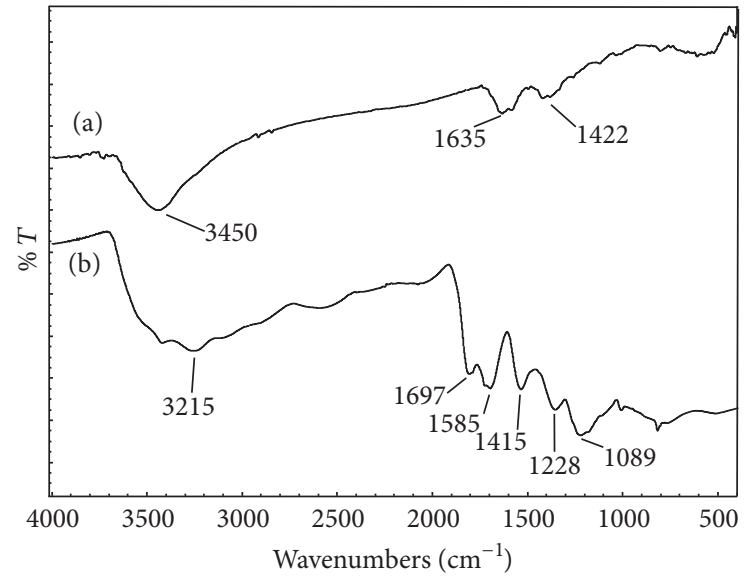

FIGURE 2: FTIR spectra of (a) carbon rod of spent batteries and (b) C-Dots.
3.2. Performance and Optimization of C-Dot Modified SPCE Sensor Strip. The analytical performances of unmodified SPCE and C-Dots-modified SPCE sensor strip were investigated by cyclic voltammetry and EIS. Several detection parameters were modulated in order to optimize the detection parameters of C-Dots modified SPCE strip. Dilute $\mathrm{HCl}$ solution was chosen as it was commonly being used as the electrolyte for electrochemical detection of heavy metal ions [21], and chloride ions $\left(\mathrm{Cl}^{-}\right)$were able to stabilize the SPCE potential [22, 23]. The effects of $\mathrm{HCl}$ concentration and mass of C-Dots on the current intensity were investigated in order to optimize the analytical performance of C-Dots modified SPCE sensor strip. As shown in Figure 3, the highest current intensity was achieved by using $0.01 \mathrm{M} \mathrm{HCl}$ as electrolyte and the deposition of $10 \mu \mathrm{g}$ of C-Dots onto SPCE. However, deposition of $20 \mu \mathrm{g}$ of C-Dots did not lead to further increase in the current intensity but resulted in a thicker C-Dots layer 


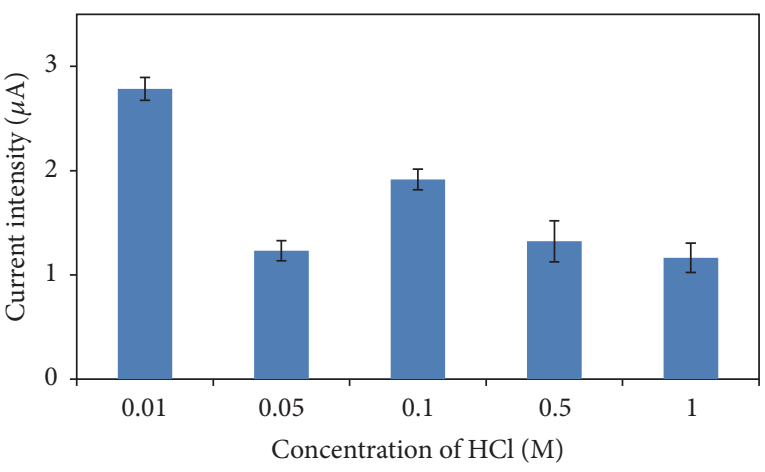

(a)

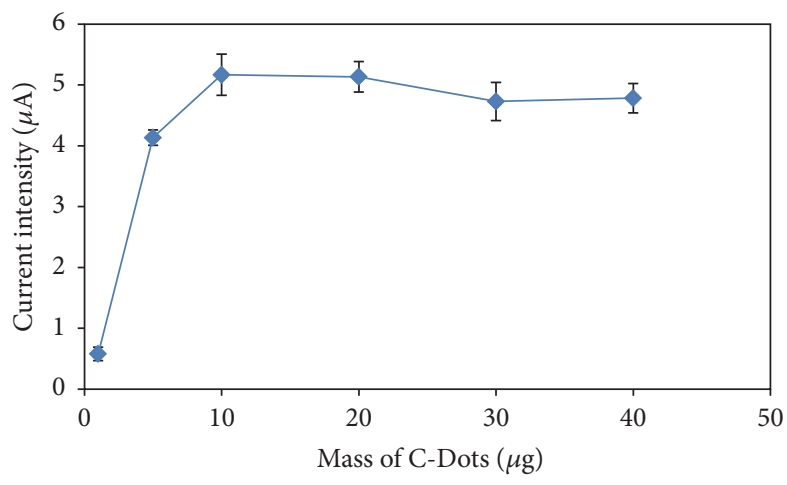

(b)

FIGURE 3: Effect of (a) concentration of $\mathrm{HCl}$ and (b) concentration of C-Dots on the current intensity of C-Dots modified SPCE sensor strip. (Error bars were calculated from the mean value, $s / n=3$.)

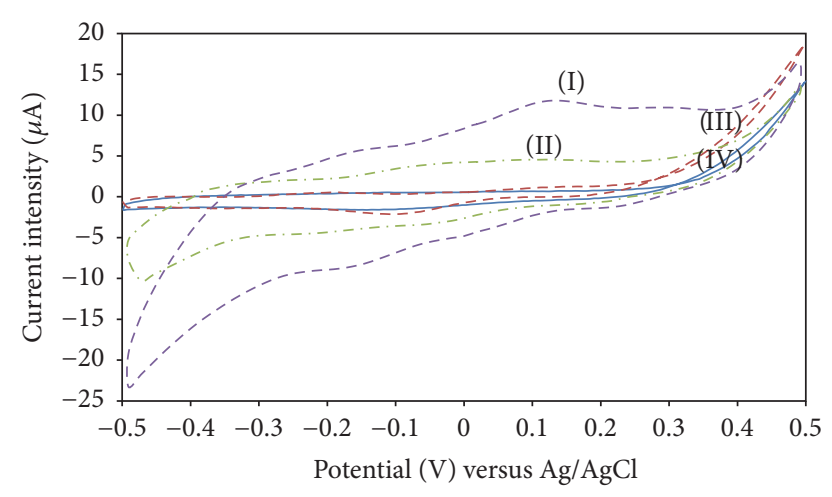

(a)

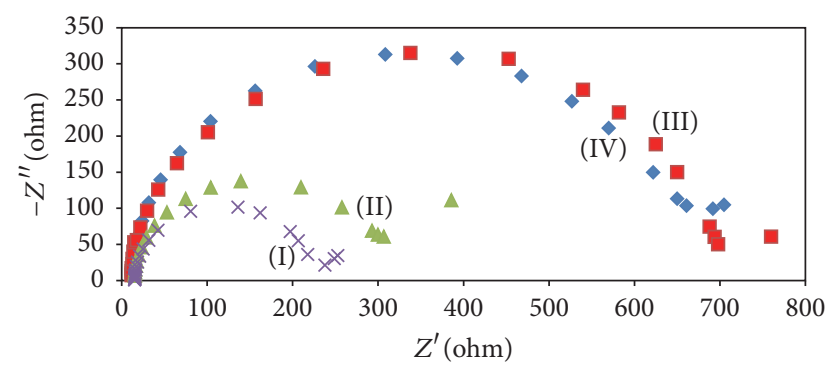

(b)

FIGURE 4: (a) Cyclic voltammogram and (b) Nyquist plot of (I) $\mathrm{Fe}^{3+}$ immobilized C-Dots modified SPCE, (II) C-Dots modified SPCE, (III) $\mathrm{Fe}^{3+}$ immobilized unmodified SPCE, and (IV) unmodified SPCE. Both CV and EIS were conducted in $0.01 \mathrm{M} \mathrm{HCl}$ at a scan rate of $100 \mathrm{mVs}^{-1}$ and within the frequency range of $0.01 \mathrm{~Hz}$ to $10.0 \mathrm{kHz}$, respectively.

which could be detached easily from the SPCE. As such, the optimum $10 \mu \mathrm{g}$ of C-Dots was deposited to modify SPCE for studies on metal ions detection.

3.3. Ferric Ions $\left(\mathrm{Fe}^{3+}\right)$ Detection by C-Dot Modified SPCE Sensor Strip. As shown in Figure 4(a) C-Dots-modified SPCE (curve II) exhibited a remarkable $734 \%$ higher anodic peak current intensity as compared with that of unmodified
SPCE (curve IV), indicating that the deposition of C-Dots had substantially enhanced the overall electrical conductivity of SPCE. Upon addition of $10 \mu \mathrm{L}$ of $25.0 \mathrm{ppm} \mathrm{Fe}^{3+}$ ions onto C-Dots-modified SPCE, the current intensity was observed to have increased substantially (curve I). However, addition of the same quantity of $\mathrm{Fe}^{3+}$ ions onto unmodified SPCE did not result in any notable change of current intensity (curve III). As shown in Figure 4 (b), both Nyquist plots of unmodified SPCE and $\mathrm{Fe}^{3+}$-unmodified SPCE were nearly identical with semicircular features of similar large diameters, indicating high electron-transfer resistance $\left(R_{\mathrm{et}}\right)$. In contrast, both CDots-modified SPCE and $\mathrm{Fe}^{3+}$ ions immobilized C-Dotsmodified SPCE showed semicircular features of substantially smaller diameter, indicating much lower $R_{\mathrm{et}}$. These observations were consistent with results of $\mathrm{CV}$.

Figure 5(a) shows the cyclic voltammograms of C-Dots modified SPCE in the presence of various concentrations of $\mathrm{Fe}^{3+}$ ions. The current intensity of C-Dots-modified SPCE was observed to increase linearly with increasing concentrations of $\mathrm{Fe}^{3+}$ ions, within the range of 0.5 to $25.0 \mathrm{ppm}$ (Figure 5(b)). Such increase in current intensity could be attributed to more $\mathrm{Fe}^{3+}$ ions being bound to $-\mathrm{COO}^{-}$groups on the surfaces of C-Dots, which led to higher electrical conductivity of the C-Dots-modified SPCE. Under optimized conditions, the LOD for the detection of $\mathrm{Fe}^{3+}$ ions by the C-Dots modified SPCE sensor strip was determined to be $0.44 \pm 0.04 \mathrm{ppm}$.

3.4. Selectivity Analysis of C-Dots Modified SPCE Sensor Strip. The selectivity of C-Dots-modified SPCE sensor strip was investigated with a wide range of metal ions including $\mathrm{Ba}^{2+}$, $\mathrm{Ca}^{2+}, \mathrm{Cd}^{2+}, \mathrm{Co}^{2+}, \mathrm{Hg}^{2+}, \mathrm{Na}^{+}, \mathrm{K}^{+}, \mathrm{Sn}^{2+}$, and $\mathrm{Zn}^{2+}$ ions which were commonly associated with heavy metal pollution in water. Selectivity tests were conducted under experimental conditions optimized in this study. As shown in Figure 6, the current intensity of C-Dots-modified SPCE sensor strip was the highest in the presence of $\mathrm{Fe}^{3+}$ ions among all metal ions evaluated. Addition of $10 \mu \mathrm{L}$ of $25.0 \mathrm{ppm}$ of $\mathrm{Fe}^{3+}$ ions had led to increase in the current intensity of C-Dots-modified 


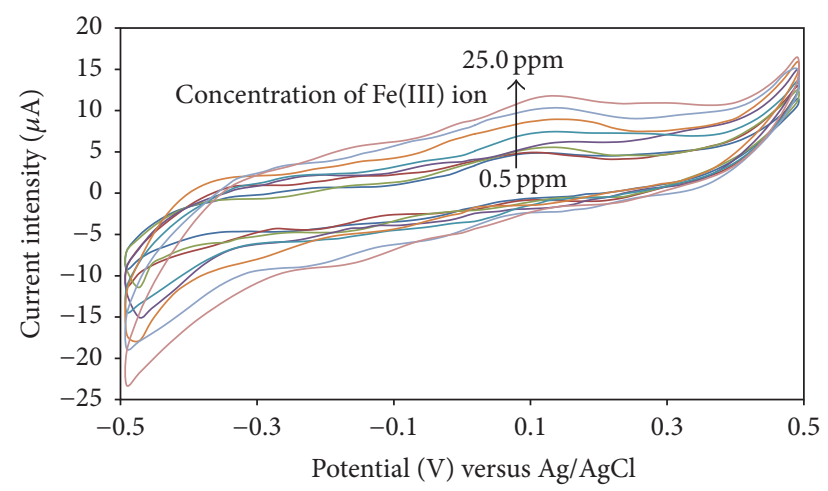

(a)

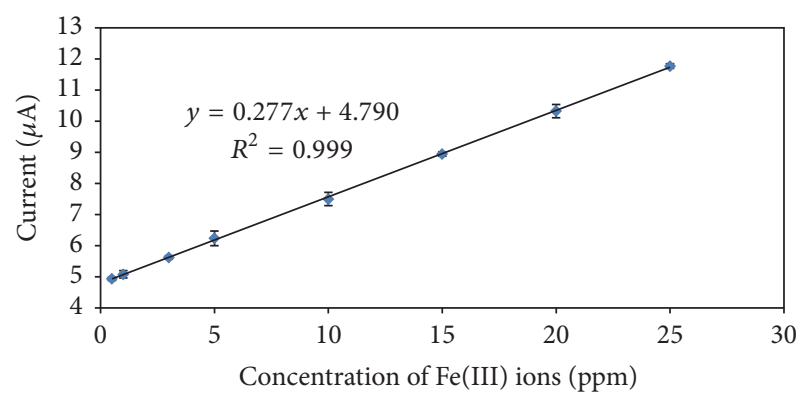

(b)

Figure 5: (a) Cyclic voltammogram of C-Dots modified SPCE with various concentrations of $\mathrm{Fe}^{3+}$ ions and (b) relationship between current intensity and $\mathrm{Fe}^{3+}$ ions concentration within the range of 0.5 to $25.0 \mathrm{ppm}$. (Error bars were calculated from the mean value, $s / n=$ 3.)

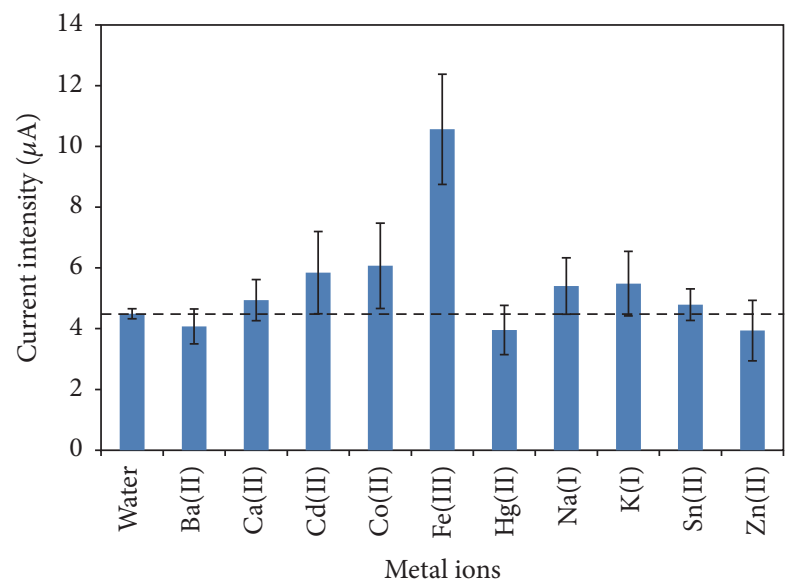

FIGURE 6: Current response of C-Dots modified SPCE for various metal ions (25.0 ppm) (water was used as the control).

SPCE sensor strip by $259 \%$ as compared to the blank signal. In contrast, all other metal ions were observed to have negligible effects on the current intensity of C-Dots-modified SPCE sensor strip. Hence, the C-Dots-modified SPCE sensor strip was observed to exhibit high selectivity towards $\mathrm{Fe}^{3+}$ ions. In addition, the interference study was conducted in order to evaluate the selectivity of C-Dots-modified SPCE sensor strip for the detection of $\mathrm{Fe}^{3+}$ ions in the presence of other
TABLE 1: Relative error in the determination of $\mathrm{Fe}^{3+}$ ions concentration in the presence of other metal ions at $10 \mathrm{ppm}$.

\begin{tabular}{lc}
\hline Metal ions & Relative error of $\mathrm{Fe}^{3+}$ ions concentration (\%) \\
\hline $\mathrm{Ba}(\mathrm{II})$ & 2.49 \\
$\mathrm{Ca}(\mathrm{II})$ & 3.48 \\
$\mathrm{Cd}(\mathrm{II})$ & 7.68 \\
$\mathrm{Co}(\mathrm{II})$ & 0.50 \\
$\mathrm{Hg}(\mathrm{II})$ & 0.81 \\
$\mathrm{~K}(\mathrm{I})$ & 6.89 \\
$\mathrm{Na}(\mathrm{I})$ & 14.85 \\
$\mathrm{Sn}(\mathrm{II})$ & 18.68 \\
$\mathrm{Zn}(\mathrm{II})$ & 1.81 \\
\hline
\end{tabular}

metal ions. The relative errors of $\mathrm{Fe}^{3+}$ ions concentration determined by the sensor strip due to interferences of other metal ions were calculated as shown in Table 1. Interferences from $\mathrm{Sn}^{2+}$ and $\mathrm{Na}^{+}$were observed to cause comparatively higher errors of $18.68 \%$ and $14.85 \%$ in the determination of $\mathrm{Fe}^{3+}$ ions concentration. The presence of $\mathrm{Sn}^{2+}$ ions on C-Dots modified SPCE sensor strip which exhibited higher current intensity than that of C-Dots modified SPCE sensor strip alone. Hence, the addition of $\mathrm{Fe}^{3+}$ ions onto the working electrode of the sensor strip would result in higher current intensity which in turn gave rise to higher relative error in the $\mathrm{Fe}^{3+}$ ions concentration determination. The selectivity of C-Dots-modified SPCE sensor strip was attributed to the presence of the carboxylate groups $\left(-\mathrm{COO}^{-}\right)$on the surfaces of $\mathrm{C}$-Dots with strong coordination affinity towards $\mathrm{Fe}^{3+}$ ions $[14,24]$. The formation of $\mathrm{Fe}^{3+}-\mathrm{COO}^{-}$complexes could have given rise to higher electrical conductivity of the sensor strip.

3.5. Real Sample Analysis. The potential application of CDots modified SPCE sensor strip for the detection and quantification of $\mathrm{Fe}^{3+}$ ions in real samples was evaluated by using samples of tap water, reverse osmosis (RO) water, and commercial mineral drinking water. Water samples were filtered with filter paper and then spiked to prepare water samples containing $10.0 \mathrm{ppm}$ of $\mathrm{Fe}^{3+}$ ions. As shown in Table 2, the $\%$ recovery of $\mathrm{Fe}^{3+}$ ions from these samples as determined by using the C-Dots modified SPCE sensor strip ranged between $92.3 \%$ and $97.5 \%$ with relative standard deviation (RSD) of $5.1 \%$ to $6.8 \%$. These analysis results were further validated against those obtained by AAS. Analysis results for all real samples obtained by both AAS and C-Dots modified SPCE sensor strips were consistent and comparable. The C-Dots modified SPCE sensor strip was shown to be sensitive and selective for the detection of $\mathrm{Fe}^{3+}$ ions in aqueous samples.

\section{Conclusion}

A disposable C-Dots modified SPCE sensor strip for sensitive and selective detection of $\mathrm{Fe}^{3+}$ ions in aqueous samples had been fabricated. C-Dots were prepared from carbon rods of spent batteries using a green electrochemical method. Under optimized conditions, the LOD for $\mathrm{Fe}^{3+}$ ions by C-Dots 
TABLE 2: Percentage recovery of spiked $\mathrm{Fe}^{3+}$ ions for various water samples using C-Dots modified SPCE sensor strips and AAS.

\begin{tabular}{|c|c|c|c|c|c|c|c|c|}
\hline \multirow[t]{2}{*}{ Real sample } & \multirow{2}{*}{$\begin{array}{c}\text { Sample } \\
\text { Fe(III) (ppm) }\end{array}$} & \multirow{2}{*}{$\begin{array}{l}\text { Spiked Fe(III) } \\
\quad(\mathrm{ppm})\end{array}$} & \multirow{2}{*}{$\begin{array}{c}\text { Measured } \\
\text { Fe(III) (ppm) }\end{array}$} & \multirow{2}{*}{$\begin{array}{l}\text { Recovery (\%) } \\
\text { AAS }\end{array}$} & \multirow[t]{2}{*}{ RSD (\%) } & $\begin{array}{c}\text { Measured } \\
\text { Fe(III) (ppm) }\end{array}$ & Recovery (\%) & $\operatorname{RSD}(\%)$ \\
\hline & & & & & & \multicolumn{3}{|c|}{ C-Dots modified SPCE sensor strip } \\
\hline Tap water & $<0.3[25]$ & 10 & 9.0100 & 89.10 & 0.90 & 9.7018 & 94.02 & 5.16 \\
\hline $\begin{array}{l}\text { Reverse osmosis } \\
\text { water }\end{array}$ & ND & 10 & 9.6215 & 96.21 & 0.10 & 9.7449 & 97.45 & 5.11 \\
\hline Mineral water & ND & 10 & 8.6015 & 86.01 & 0.30 & 9.2336 & 92.34 & 6.85 \\
\hline
\end{tabular}

$\mathrm{ND}=$ not detected.

modified SPCE sensor strip was determined to be $0.44 \pm$ $0.04 \mathrm{ppm}$. High percentage recovery of $\mathrm{Fe}^{3+}$ ions from various water samples with low \% RSD and low \% relative error in the presence of other metal ions showed that the C-Dots modified SPCE sensor strip could potentially be used for sensitive and selective detection of $\mathrm{Fe}^{3+}$ ions in real samples. The detection limit can further be improved in the future by doping the C-Dots with other elements such as nitrogen $(\mathrm{N})$ and sulfur (S) for more sensitive detection and application in water quality studies.

\section{Competing Interests}

The authors declare that there are no competing interests regarding the publication of this paper. The authors of this paper have no direct financial relation with the commercial entities mentioned in this paper.

\section{Acknowledgments}

This work was funded by Ministry of Higher Education, Malaysia, via the award of a Exploratory Research Grant [Grant no. ERGS/STG05(01)/1005/2013(02)]. MyBrain15 and Zamalah Graduate Scholarship (ESSU) were gratefully acknowledged.

\section{References}

[1] A. Kamal, N. Kumar, V. Bhalla, M. Kumar, and R. K. Mahajan, "Rhodamine-dimethyliminocinnamyl based electrochemical sensors for selective detection of iron (II)," Sensors and Actuators, B: Chemical, vol. 190, pp. 127-133, 2014.

[2] H. Bagheri, A. Gholami, and A. Najafi, "Simultaneous preconcentration and speciation of iron(II) and iron(III) in water samples by 2 -mercaptobenzimidazole-silica gel sorbent and flow injection analysis system," Analytica Chimica Acta, vol. 424, no. 2, pp. 233-242, 2000.

[3] X. Pu, B. Hu, Z. Jiang, and C. Huang, "Speciation of dissolved iron(II) and iron(III) in environmental water samples by gallic acid-modified nanometer-sized alumina micro-column separation and ICP-MS determination," Analyst, vol. 130, no. 8, pp. 1175-1181, 2005.

[4] L. Xu, W. Mao, J. Huang et al., "Economical, green route to highly fluorescence intensity carbon materials based on ligninsulfonate/graphene quantum dots composites: application as excellent fluorescent sensing platform for detection of $\mathrm{Fe}^{3+}$ ions," Sensors and Actuators, B: Chemical, vol. 230, pp. 54-60, 2016.

[5] S. Altamura and M. U. Muckenthaler, "Iron toxicity in diseases of aging: alzheimer's disease, parkinson's disease and atherosclerosis," Journal of Alzheimer's Disease, vol. 16, no. 4, pp. 879-895, 2009.

[6] L. Zecca, M. B. H. Youdim, P. Riederer, J. R. Connor, and R. R. Crichton, "Iron, brain ageing and neurodegenerative disorders," Nature Reviews Neuroscience, vol. 5, no. 11, pp. 863-873, 2004.

[7] J. Li, Q. Wang, Z. Guo et al., "Highly selective fluorescent chemosensor for detection of $\mathrm{Fe}^{3+}$ based on $\mathrm{Fe}_{3} \mathrm{O}_{4} @ \mathrm{ZnO}$," Scientific Reports, vol. 6, Article ID 23558, 2016.

[8] J.-A. Annie Ho, H.-C. Chang, and W.-T. Su, "DOPA-mediated reduction allows the facile synthesis of fluorescent gold nanoclusters for use as sensing probes for ferric ions," Analytical Chemistry, vol. 84, no. 7, pp. 3246-3253, 2012.

[9] Y.-C. Chen, Y.-L. Jian, K.-H. Chiu, and H.-K. Yak, "Simultaneous speciation of iron(II) and iron(III) by ion chromatography with chemiluminescence detection," Analytical Sciences, vol. 28, no. 8, pp. 795-799, 2012.

[10] A. K. Tareen, I. N. Sultan, P. Parakulsuksatid et al., "Detection of heavy metals $(\mathrm{Pb}, \mathrm{Sb}, \mathrm{Al}, \mathrm{As})$ through atomic absorption spectroscopy from drinking water of District Pishin, Balochistan, Pakistan," International Journal of Current Microbiology and Applied Sciences, vol. 3, no. 1, pp. 299-308, 2014.

[11] M. M. Ali, M. L. Ali, M. S. Islam, and M. Z. Rahman, "Preliminary assessment of heavy metals in water and sediment of Karnaphuli River, Bangladesh," Environmental Nanotechnology, Monitoring \& Management, vol. 5, pp. 27-35, 2016.

[12] V. K. Gupta, A. K. Jain, S. Agarwal, and G. Maheshwari, "An iron(III) ion-selective sensor based on a $\mu$-bis(tridentate) ligand," Talanta, vol. 71, no. 5, pp. 1964-1968, 2007.

[13] D. Vlascici, E. Fagadar-Cosma, I. Popa, V. Chiriac, and M. GilAgusti, "A Novel sensor for monitoring of iron(III) ions based on porphyrins," Sensors, vol. 12, no. 6, pp. 8193-8203, 2012.

[14] H. A. Zamani, M. R. Abedi, and M. R. Ganjali, "Monitoring of iron(III) ions with a $\mathrm{Fe}^{3+}$-pvc membrane sensor based on 4, 4'dimethoxybenzil bisthiosemicarbazone," Journal of the Chilean Chemical Society, vol. 54, no. 2, pp. 186-190, 2009.

[15] J. F. Y. Fong, S. F. Chin, and S. M. Ng, "Facile synthesis of carbon nanoparticles from sodium alginate via ultrasonic-assisted nano-precipitation and thermal acid dehydration for ferric ion sensing," Sensors and Actuators B: Chemical, vol. 209, pp. 9971004, 2015.

[16] H. Ming, Z. Ma, Y. Liu et al., "Large scale electrochemical synthesis of high quality carbon nanodots and their photocatalytic property," Dalton Transactions, vol. 41, no. 31, pp. 9526-9531, 2012. 
[17] J. Deng, Q. Lu, N. Mi et al., "Electrochemical synthesis of carbon nanodots directly from alcohols," Chemistry-A European Journal, vol. 20, no. 17, pp. 4993-4999, 2014.

[18] S. Zhao, C. Li, J. Liu et al., "Carbon quantum dots $/ \mathrm{SnO}_{2}-\mathrm{Co}_{3} \mathrm{O}_{4}$ composite for highly efficient electrochemical water oxidation," Carbon, vol. 92, pp. 64-73, 2015.

[19] Y. Hou, Q. Lu, H. Wang, H. Li, Y. Zhang, and S. Zhang, "One-pot electrochemical synthesis of carbon dots $/ \mathrm{TiO}{ }_{2}$ nanocomposites with excellent visible light photocatalytic activity," Materials Letters, vol. 173, pp. 13-17, 2016.

[20] Y. Hou, Q. Lu, J. Deng, H. Li, and Y. Zhang, "One-pot electrochemical synthesis of functionalized fluorescent carbon dots and their selective sensing for mercury ion," Analytica Chimica Acta, vol. 866, pp. 69-74, 2015.

[21] I. Palchetti, S. Laschi, and M. Mascini, "Miniaturised strippingbased carbon modified sensor for in field analysis of heavy metals," Analytica Chimica Acta, vol. 530, no. 1, pp. 61-67, 2005.

[22] R. Güell, G. Aragay, C. Fontàs, E. Anticó, and A. Merkoçi, “Sensitive and stable monitoring of lead and cadmium in seawater using screen-printed electrode and electrochemical stripping analysis," Analytica Chimica Acta, vol. 627, no. 2, pp. 219-224, 2008.

[23] S. Cinti, F. Santella, D. Moscone, and F. Arduini, " $\mathrm{Hg}^{2+}$ detection using a disposable and miniaturized screen-printed electrode modified with nanocomposite carbon black and gold nanoparticles," Environmental Science and Pollution Research, vol. 23, no. 9, pp. 8192-8199, 2016.

[24] Y.-L. Zhang, L. Wang, H.-C. Zhang et al., "Graphitic carbon quantum dots as a fluorescent sensing platform for highly efficient detection of $\mathrm{Fe}^{3+}$ ions," RSC Advances, vol. 3, no. 11, pp. 3733-3738, 2013.

[25] World Health Organization, Guidelines for Drinking-Water Quality, vol. 1, World Health Organization, Geneva, Switzerland, 3rd edition, 2008. 


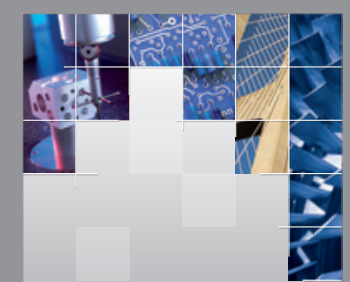

\section{Enfincering}
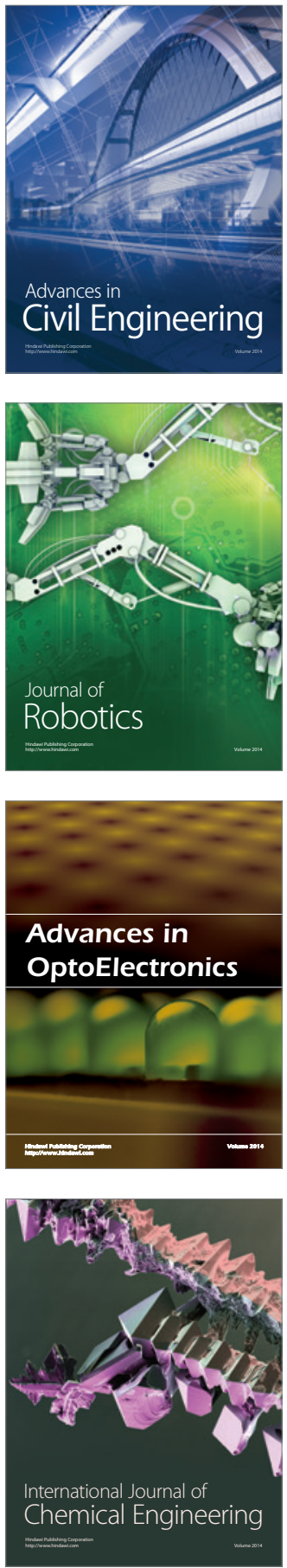

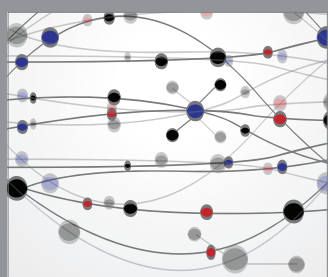

The Scientific World Journal

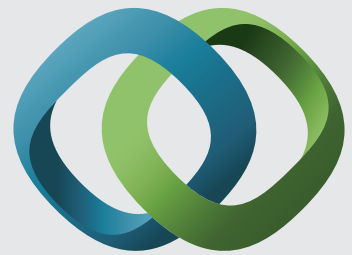

\section{Hindawi}

Submit your manuscripts at

https://www.hindawi.com
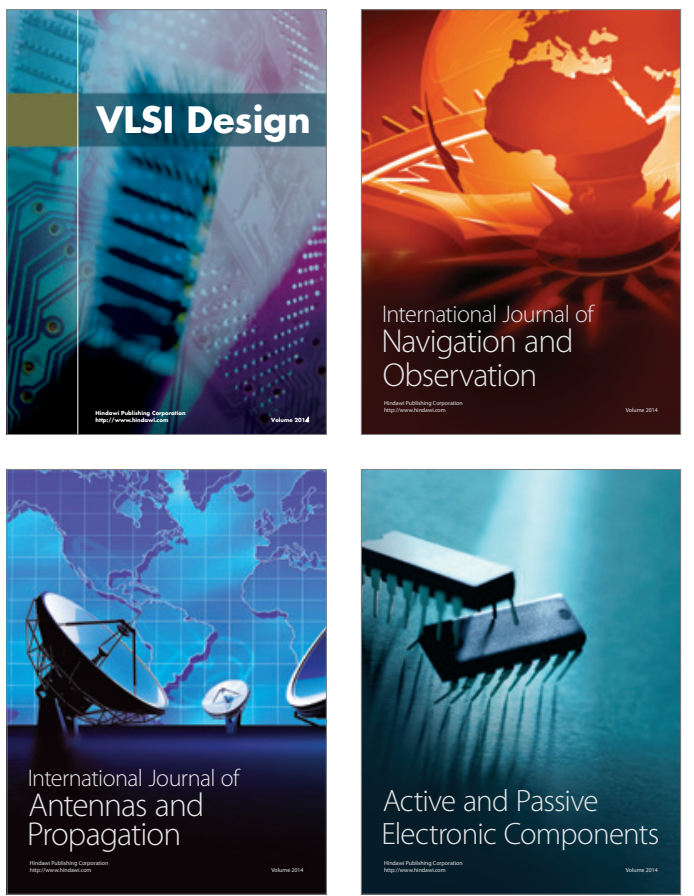
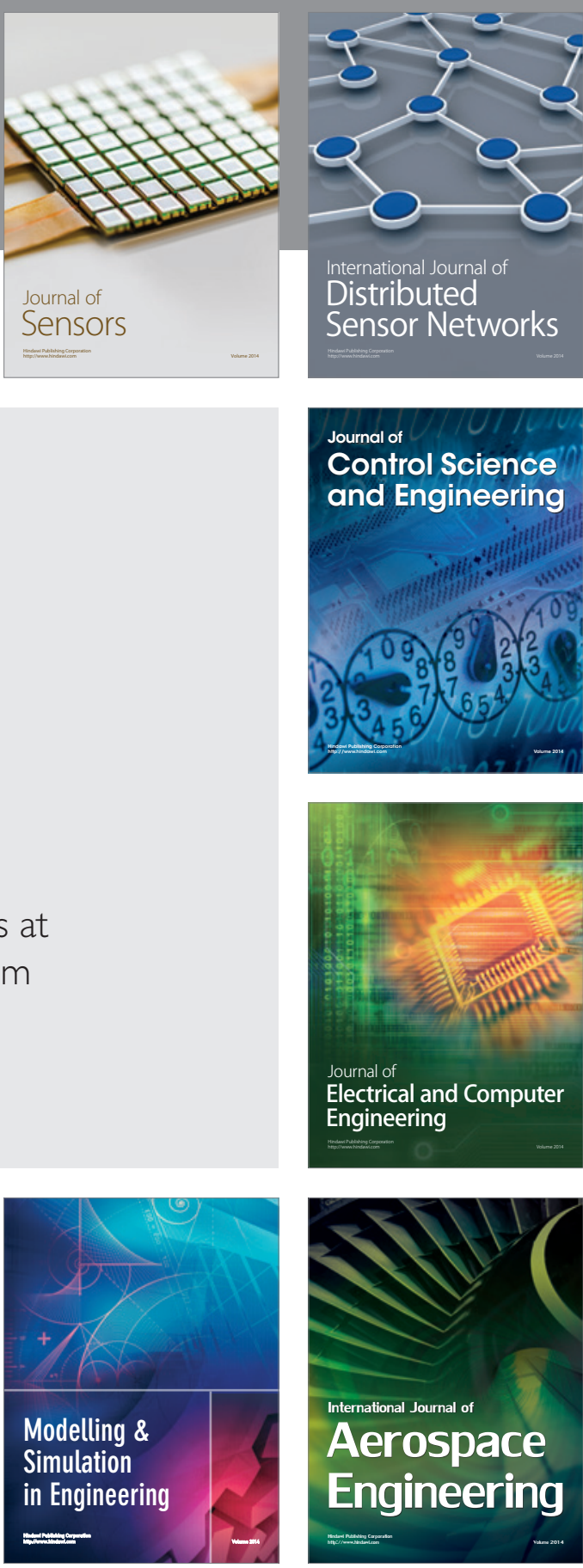

International Journal of

Distributed

Sensor Networks

$-$

Joumal of

Control Science

and Engineering
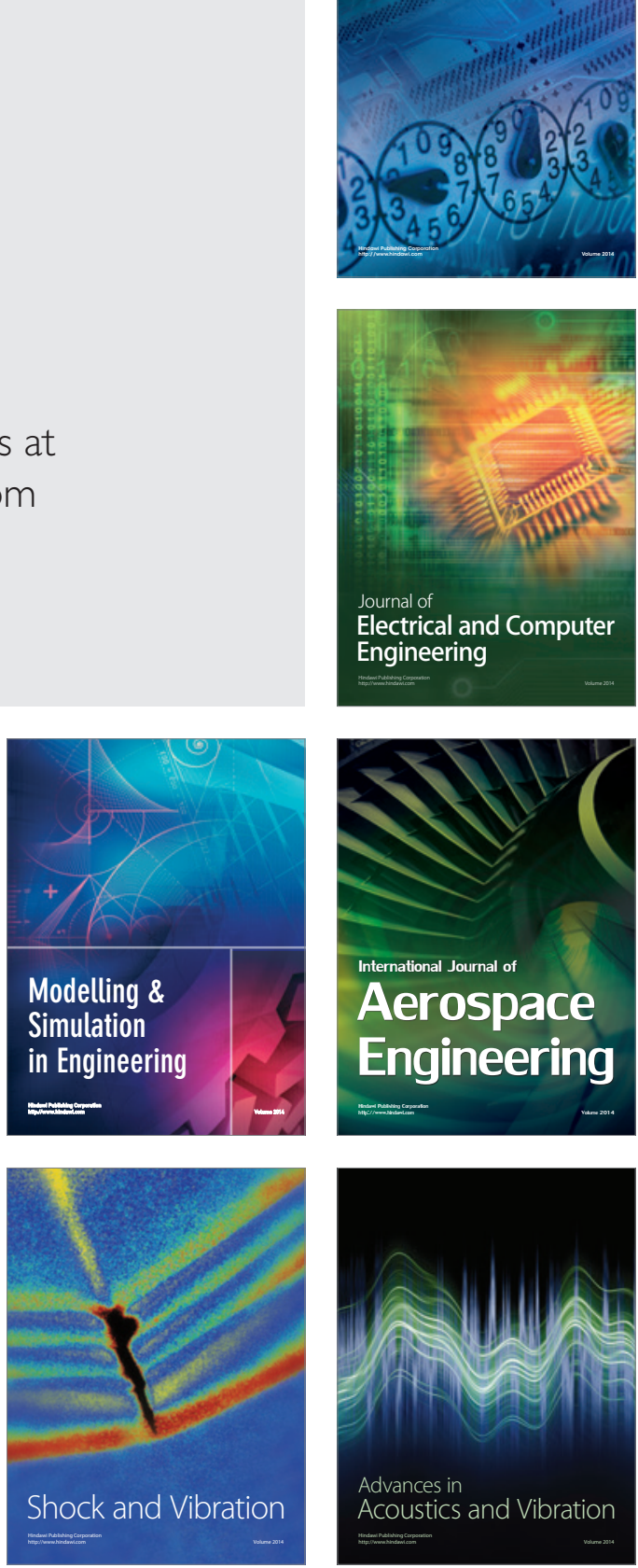